CZASOPISMO INŻYNIERII LĄDOWEJ, ŚRODOWISKA I ARCHITEKTURY JOURNAL OF CIVIL ENGINEERING, ENVIRONMENT AND ARCHITECTURE

JCEEA, t. XXXII, z. 62 (3/I/15), lipiec-wrzesień 2015, s. 477-486

\author{
Marek URBANIK ${ }^{1}$ \\ Barbara TCHÓRZEWSKA-CIEŚLAK ${ }^{2}$
}

\title{
ANALIZA STANU INFRASTRUKTURY GAZOCIĄGOWEJ ORAZ ZDARZEŃ AWARYJNYCH W PODSYSTEMIE DOSTAWY GAZU ZIEMNEGO W POLSCE
}

\begin{abstract}
Coraz większe zapotrzebowanie na energię powoduje także rosnącą emisję zanieczyszczeń do atmosfery. Dlatego też należy szukać takich źródeł energii, które będą powodować mniejsze zanieczyszczenie środowiska. Takim źródłem energii jest gaz ziemny, który podczas spalania emituje mniej szkodliwych związków w porównaniu $\mathrm{z}$ ropą naftową czy węglem. $\mathrm{Z}$ tego też względu paliwo to, znajduje coraz większe zastosowanie zarówno w przemyśle, motoryzacji czy w gospodarstwach domowych. Ze względu na coraz szersze zastosowanie zasadnym wydaje się zmniejszyć ryzyko wystąpienia awarii gazociągu, ponieważ każda awaria zakłóca dostawy tego paliwa, a to również może zakłócać pracę odbiorców. Awaria gazociągu może nieść ze sobą poważne konsekwencje w postaci strat materialnych czy zabitych osób. Przykładem jest awaria w Janowie Przygodzkim, o której wspomniano w artykule.

W pracy przedstawiono analizę stanu infrastruktury gazociągowej w Polsce. W artykule wyróżniono czynniki będące przyczynami zdarzeń awaryjnych oraz ich analizę. Przyczynami zdarzeń awaryjnych w podsystemie dystrybucji gazu ziemnego są, min.: zły stan techniczny gazociągów oraz błędy związane z zarządzaniem i pracą operatora.
\end{abstract}

Słowa kluczowe: zdarzenia awaryjne, podsystem dostawy gazu, przyczyny awarii, stan infrastruktury gazociągowej

\section{Wprowadzenie}

Rozwój cywilizacyjny pociąga za sobą wzrost zapotrzebowania na energię. $\mathrm{Z}$ drugiej jednak strony większe zużycie energii pociąga za sobą wzrost emisji szkodliwych związków do atmosfery. Z tego względu należy szukać takich źródeł energii, które będą emitować jak najmniej zanieczyszczeń. Takim źródłem

${ }^{1}$ Marek Urbanik, Politechnika Rzeszowska

2 Autor do korespondencji/corresponding author: Barbara Tchórzewska-Cieślak, Politechnika Rzeszowska, Wydział Budownictwa, Inżynierii Środowiska i Architektury, al. Powstańców Warszawy 6, 35-959 Rzeszów, tel. 17 8651435, cbarbara@prz.edu.pl 
energii jest gaz ziemny, który coraz częściej stosowany jest nie tylko w gospodarstwach domowych ale także w przemyśle [7, 12, 13]. W ostatnim czasie, można zauważyć wzrost produkcji energii elektrycznej przy wykorzystaniu gazu ziemnego. Biorąc pod uwagę zalety gazu ziemnego jako źródła energii szacuje się, że zapotrzebowanie na to paliwo będzie systematycznie rosło (rys.1).

Zwiększające się zapotrzebowanie na gaz ziemny prowadzi do rozbudowy systemu gazociągów w celu dostawy gazu do coraz większej liczby odbiorców. Duży a co za tym idzie skomplikowany układ gazociągu jest bardziej podatny na awarie, które negatywnie wpływają na systematyczność dostaw. Dlatego też, zasadne jest bieżące monitorowanie występujących awarii na przewodach gazociągowych chociażby w celu wyeliminowania usterek przy budowie następnych gazociągów.

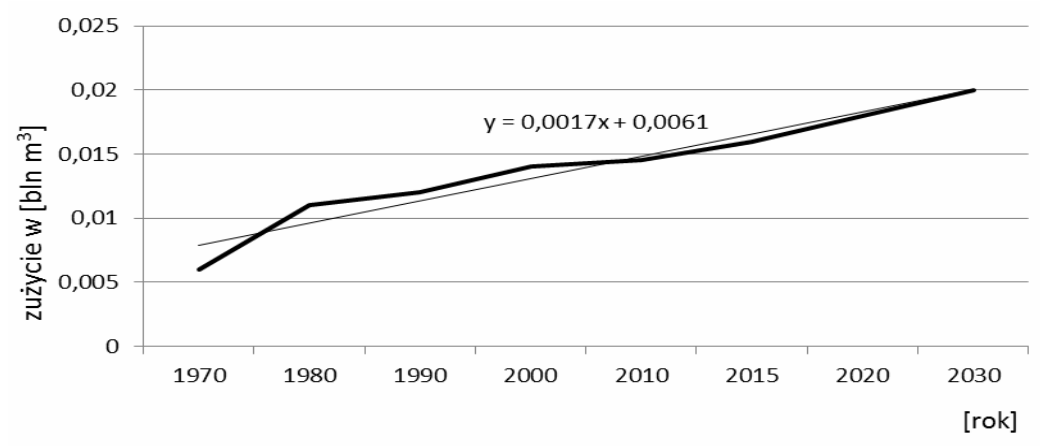

Rys. 1. Prognoza zużycia gazu ziemnego w Polsce, opracowano na podstawie [1]

Fig. 1. Prognosis of natural gas consumption in Poland, developed on the basis [1]

\section{Stan infrastruktury gazociągowej w Polsce}

Dystrybucja gazu ziemnego w naszym kraju odbywa się siecią gazociągów przesyłowych obsługiwanych przez Operatora Gazociągów Przesyłowych Gaz System S.A. oraz siecią gazociągów lokalnych Operatorów Sieci Dystrybucyjnych - Spółek Gazownictwa.

Do głównych zadań operatora systemu przesyłowego gazu należy [3, 8]:

- dostarczenie gazu o odpowiednich parametrach do odbiorcy,

- prowadzenie konserwacji i remontów gazociągów,

- informowanie potencjalnych użytkowników o sposobie podłączenia do sieci gazowej,

- dostarczanie każdemu operatorowi systemu przesyłowego, magazynowego, dystrybucyjnego oraz systemu LNG dostatecznej ilości informacji gwarantujących możliwość prowadzenia transportu i magazynowania gazu ziemnego w sposób właściwy dla bezpiecznego i efektywnego działania połączonych systemów. 
Obecnie infrastruktura przesyłowa gazu ziemnego w Polsce składa się z następujących elementów [14]:

- 57 węzłów gazowych,

- 14 tłoczni gazu,

- 884 stacji gazowych,

- długość sieci przesyłowych wynosi $10323 \mathrm{~km}$.

Gaz ziemny przesyłany jest gazociągami wysokiego, średniego i niskiego ciśnienia. Ciśnienie gazu w poszczególnych gazociągach jest następujące [6]:

- gazociąg wysokiego ciśnienia, powyżej 1,6 MPa,

- gazociąg podwyższonego ciśnienia 0,5-1,6 $\mathrm{MPa}$,

- gazociąg średniego ciśnienia $10 \mathrm{kPa}-0,5 \mathrm{MPa}$,

- gazociąg niskiego ciśnienia do $10 \mathrm{kPa}$.

Pod względem czasu eksploatacji największą grupę stanowią gazociągi o czasie eksploatacji 36-40 lat, łączna długość tych gazociągów wynosi 1887 km (rys.2). Najmniejszą grupę stanowią gazociągi eksploatowane 56-60 lat, których łączna długość wynosi $19 \mathrm{~km}$. Długość najmłodszych gazociągów wynosi $337 \mathrm{~km}$ a czas ich eksploatacji wynosi do 5 lat. Warto zauważyć, że w Polsce do tej pory eksploatowane są gazociągi w wieku 71-80 lat o kumulatywnej długości $211 \mathrm{~km}[5]$.

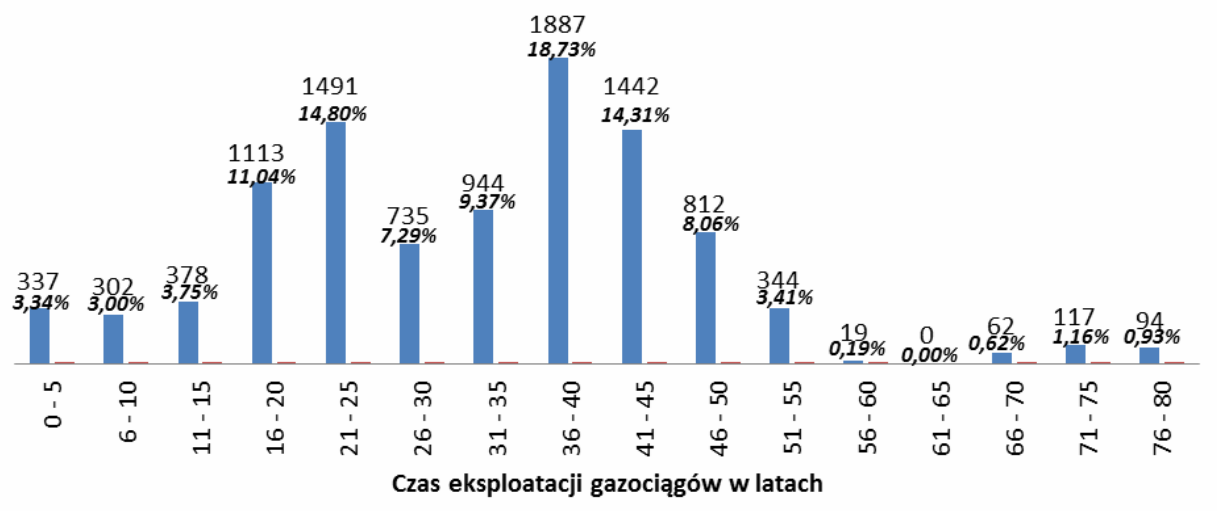

Rys. 2. Długość gazociągów w kilometrach i procentowo w zależności od czasu eksploatacji, opracowano na podstawie [5]

Fig. 2. The length of gas pipelines in kilometers and in the percentage depending on the time of operation, developed on the basis [5]

Istotną rolę $\mathrm{w}$ Polskiej infrastrukturze gazowej stanowią podziemne magazyny gazu. Stanowią zabezpieczenie dostaw gazu w przypadku gdy dostawa tego paliwa poprzez gazociągi jest niemożliwa np. z powodu braku gazu od dostawcy. Obecnie w Polsce znajduje się sześć podziemnych magazynów gazu (rys. 3). Magazyny te są zlokalizowane w wyczerpanych złożach gazu oraz 
w solnych kawernach [2]. Z pośród istniejących sześciu magazynów gazu trzy $\mathrm{z}$ nich są rozbudowywane, natomiast kolejne trzy są w budowie [6]. Parametry poszczególnych magazynów są podane w tab. 1.

Tabela 1. Parametry podziemnych zbiorników gazu ziemnego w Polsce, opracowano na podstawie [2]

Table 1. Parameters of underground storage tanks of natural gas in Poland, developed on the basis [2]

\begin{tabular}{|c|c|c|c|c|c|c|}
\hline \multirow[t]{2}{*}{$\begin{array}{c}\text { Miejsce } \\
\text { lokalizacji } \\
\text { magazynu }\end{array}$} & \multicolumn{2}{|c|}{ Pojemność $\left[\mathrm{mln} \mathrm{m} \mathbf{m}^{3}\right]$} & \multirow{2}{*}{$\begin{array}{c}\text { Maksymalne } \\
\text { ciśnienie } \\
\text { zatłaczania } \\
{[\mathrm{MPa}]}\end{array}$} & \multicolumn{2}{|c|}{$\begin{array}{c}\text { Maksymalna } \\
\text { wydajność } \\
\text { [mln m²/dobę] }\end{array}$} & \multirow[t]{2}{*}{$\begin{array}{c}\text { Czas } \\
\text { odbioru } \\
\text { [dni] }\end{array}$} \\
\hline & czynna & buforowa & & zatłaczania & odbioru & \\
\hline Brzeźnica & 65 & 76,9 & 4,5 & 0,9 & 0,8 & 100 \\
\hline Husów & 350 & 500 & 12 & 2,6 & 5,8 & 90 \\
\hline Mogilno & 370 & 171,1 & 21,3 & 9,6 & 20,6 & 32 \\
\hline Strachocina & 150 & 530,9 & 4 & 1,6 & 1,2 & 166 \\
\hline Swarzów & 90 & 111 & 9,5 & 0,9 & 1 & 120 \\
\hline Wierzchowice & 575 & 5157,1 & 10 & 3,6 & 4,8 & 150 \\
\hline Bonikowo & 200 & - & - & 1,7 & 2,4 & - \\
\hline Daszewo & 30 & - & - & 0,2 & 0,4 & - \\
\hline Kosakowo & 250 & - & - & 2,4 & 9,6 & - \\
\hline
\end{tabular}

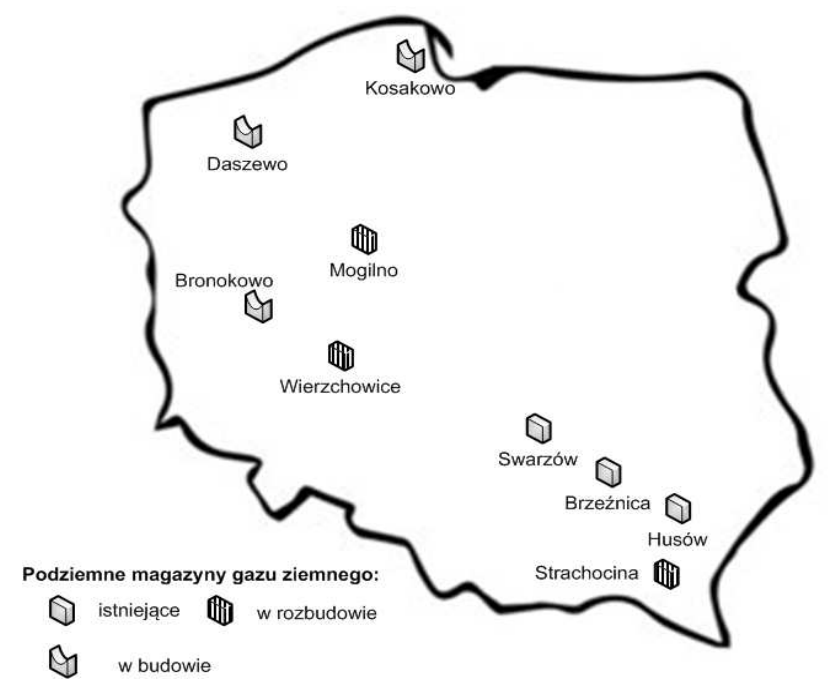

Rys. 3. Rozmieszczenie podziemnych magazynów gazu ziemnego w Polsce, opracowano na podstawie [2]

Fig. 3. Distribution of underground natural gas storage tanks in Poland, developed on the basis [2] 
Sieci gazociągowe oprócz podziemnych magazynów gazu mogą być zasilane gazem z terminali LNG. Na dzień dzisiejszy w Polsce nie ma działającego terminalu LNG, natomiast jeden znajduje się w budowie (w Świnoujściu). Technologia LNG polega na dostarczeniu gazu do terminalu w postaci skroplonej głównie przez statki powszechnie znane jako gazowce. W celu skroplenia gazu ziemnego konieczne jest jego schłodzenie do temperatury minus $161^{\circ} \mathrm{C}$. Przed dostarczeniem gazu do sieci gazociągowej, skroplony gaz ziemny należy poddać procesowi regazyfikacji, czyli ponownemu przekształceniu w fazę gazową. Terminal LNG budowany w Świnoujściu umożliwi odbiór $5 \mathrm{mld}^{3}$ gazu rocznie. Następnie w zależności od wzrostu zapotrzebowania na gaz ziemny zakłada się zwiększenie wydajności terminalu do regazyfikacji do $7,5 \mathrm{mld} \mathrm{m}^{3}$ rocznie, co będzie stanowiło ok. $50 \%$ rocznego zapotrzebowania. W przyszłości terminal LNG będzie pełnił bardzo ważną role $\mathrm{w}$ infrastrukturze gazowej, ponieważ umożliwi uniezależnienie się od dostaw gazu z jednego źródła [4].

\section{Metodyka badań}

Awaria obiektu technicznego to nic innego jak nagła utrata jego sprawności. Stwierdzenie wystąpienia awarii jest stosunkowo łatwe (np. po nieprawidłowych parametrach pracy obiektu technicznego), ale ustalenie przyczyny wystąpienia awarii nierzadko stwarza problemy, ponieważ na wystąpienie awarii może mieć wiele czynników jednocześnie. W przypadku gazociągów, głównym symptomem świadczącym o wystąpieniu awarii jest spadek ciśnienia gazu spowodowany rozszczelnieniem przewodu oraz woń wypływającego z niego gazu. Kiedy pierwsze objawy awarii gazociągu nie zostaną zauważone następnym efektem może być zapłon a w konsekwencji wybuch ulatniającego się gazu. Przyczyny awarii można podzielić następująco [6, 9-11]:

- zależne od człowieka, np. celowe uszkodzenie gazociągu lub niewłaściwe jego wykonanie,

- niezależne od człowieka, np. oddziaływanie czynników środowiska (temperatura, wilgoć), starzenie materiału.

$\mathrm{Z}$ reguły awaria gazociągu wiąże się $\mathrm{z}$ utratą szczelności, która skutkuje wyciekiem gazu. W celu oszacowania strat związanych $\mathrm{z}$ awarią konieczne jest określenie ile gazu wydostało się z gazociągu w czasie awarii. Ilość gazu, która wydostała się z gazociągu można obliczyć z zależności:

$$
\Delta V=11,88 \cdot F \cdot p \cdot \tau \cdot(1 / \mathrm{T})^{1 / 2}
$$

gdzie: $\Delta \mathrm{V}$ - objętość uchodzącego gazu, w warunkach normalnych $\left[\mathrm{m}^{3}\right]$ (warunki normalne, temperatura $\mathrm{T}=273,15 \mathrm{~K}$, ciśnienie $\mathrm{p}=101325 \mathrm{~Pa}, \mathrm{~F}-$ powierzchnia szczeliny $\left[\mathrm{cm}^{2}\right], \mathrm{T}-$ temperatura gazu $[\mathrm{K}], \rho-$ ciśnienie absolutne gazu w gazociągu przed awarią $[\mathrm{kPa}], \tau$ - czas uchodzenia gazu podczas trwania awarii [h]. 
Główny operator sieci gazowych Gaz-System na swoich gazociągach od roku 2011 do 2014 odnotował 110 awarii (rys. 4).

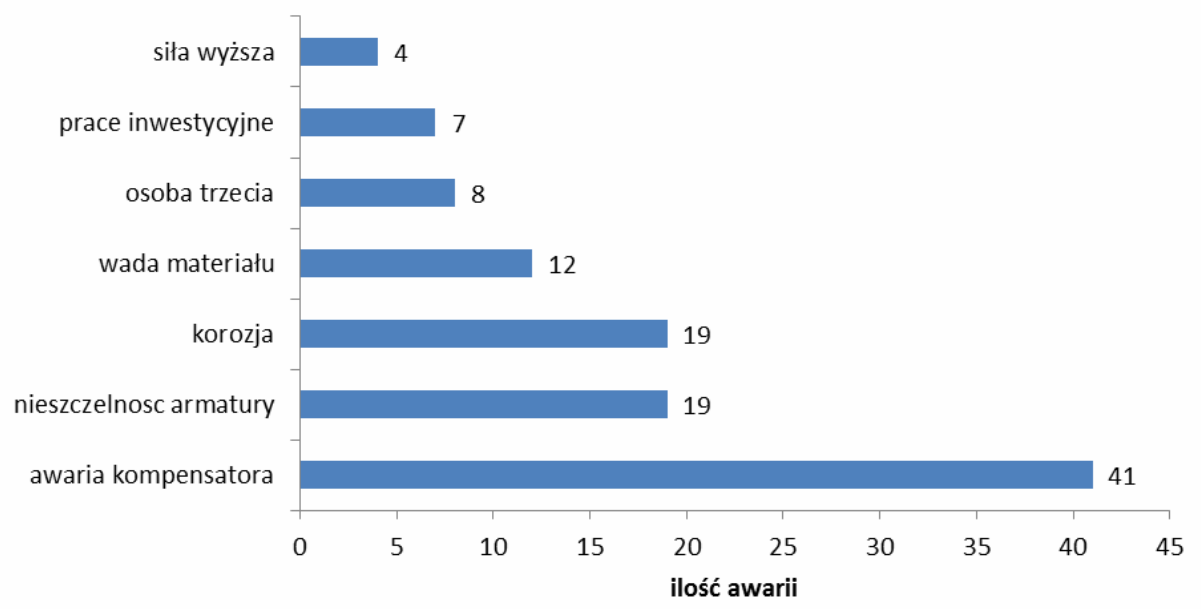

Rys. 4. Liczba awarii na gazociągach według przyczyn w latach 2011-2014, opracowano na podstawie [5]

Fig. 4. The number of failures on pipelines depending on causes in 2011-2014, developed on the basis [5]

Najwięcej awarii wywołał kompensator, który odpowiada za redukcję naprężeń w gazociągu powstałych w wyniku oddziaływania temperatury lub osuwania się gruntu. Kompensatory ulegały uszkodzeniu częściej na terenach górniczych [5].

Następną grupę przyczyn awarii po kompensatorach stanowią nieszczelność armatury i korozja. Najmniej awarii wystąpiło z powodu sił wyższych np. czynników atmosferycznych.

Analizując przyczyny powstawania awarii na gazociągach można również wyodrębnić awarie spowodowane przez wady techniczne, jak: awaria kompensatora, korozja czy wada materiału oraz przez inne czynniki nietechniczne takie jak: prace inwestycyjne, działanie osób trzecich lub siły wyższej (rys. 5). Uszkodzenia powstałe podczas prac inwestycyjnych są związane z uszkodzeniem gazociągów podczas takich prac jak np.: naprawa istniejącego gazociągu, budowa drogi.

Biorąc pod uwagę wiek gazociągu, najwięcej awarii w latach 2011-2013 wystąpiło na gazociągach, których okres eksploatacji wynosi 36-40 lat (20 awarii) oraz 11-15 lat (19 awarii), (rys. 6). 


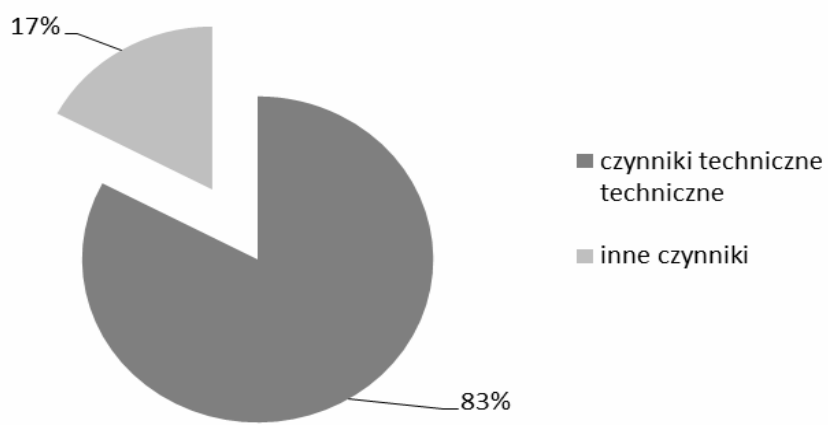

Rys. 5. Podział przyczyn awarii w latach 2011-2014, opracowano na podstawie [5]

Fig. 5. Distribution of failure causes in 2011-2014, developed on the basis [5]



Rys. 6. Liczba awarii, czas eksploatacji i długość gazociągu, opracowano na podstawie [5]

Fig. 6. The number of failures, operating hours and the pipeline length, developed on the basis [5]

W rozpatrywanym okresie czasu najmniej awarii było na gazociągach w wieku 76-80 lat (trzy awarie) oraz na gazociągach, których lata eksploatacji wynoszą 51-55 i 66-70 lat (cztery awarie). Na gazociągach, których czas użytkowania wynosi do 5 lat, 6-10 lat, 56-65 i 71-75 lat nie wystąpiły awarie. 


\section{Podsumowanie}

Ciągle rozrastające się miasta i wsie będą powodowały konieczność rozbudowy systemu gazociągów, co może zwiększyć prawdopodobieństwo awarii gazociągu. Awaria w pewnych okolicznościach może pociągnąć za sobą tragiczne skutki - np. śmierć ludzi i duże straty materialne, np. awaria gazociągu w Janowie Przygodzkim na gazociągu DN 500 Odolanów - Adamów. W tym przypadku awaria przewodu gazociągowego była spowodowana jego uszkodzeniem podczas budowy nowego gazociągu DN 700 obok istniejącego DN 500. Według komisji prowadzącej śledztwo do katastrofy przyczyniły się [5]:

- ,parcie niewłaściwie i zbyt wysoko zgromadzonych mas ziemnych na odkryty podczas prowadzenia robót budowlanych i niezabezpieczony gazociąg, w efekcie czego nastąpiło obsunięcie skarpy wraz z gazociągiem DN 500 do wykopu wykonanego pod gazociąg DN 700, oraz

- rozszczelnienie - przerwanie gazociągu DN 500 w miejscu wadliwie wykonanego i niedopuszczalnego w konstrukcjach inżynierskich tzw. spawu czołowego".

Przykład tej katastrofy pokazuje, że aby zmniejszyć prawdopodobieństwo awarii gazociągu należy:

- skrupulatnie prowadzić dokumentacją projektową,

- szczegółowo sprawdzać czy prace prowadzone na gazociągach są prowadzone zgodnie z dokumentacją i z zachowaniem wszelkich norm bezpieczeństwa,

- okresowo prowadzić kontrolę stanu technicznego gazociągów, a w miejscach newralgicznych (np. tereny górnicze lub tereny gdzie występują osuwiska) wprowadzać częstsze inspekcje.

Jak widać z powyższego powodem tej awarii były czynniki związane z pracami inwestycyjnymi (budowa gazociągu) oraz technicznymi (wadliwie wykonana spoina). Skutki tego zdarzenia to śmierć dwóch osób i zniszczone zabudowania. Wypadki o takich rozmiarach nie występują często na gazociągach. Operatorzy zarządzający infrastrukturą gazową w sposób ciągły prowadzą doskonalenie metod kontroli przewodów gazociągowych i ciągle opracowują nowe procedury napraw i budowy gazociągów, aby ryzyko awarii było jak najmniejsze.

\section{Literatura}

[1] http://infolupki.pgi.gov.pl/pl/gaz-ziemny/gaz-ziemny-surowiec-strategiczny [dostęp 28.09.2015 r.].

[2] http://www.gazownictwopolskie.pl/technologie/magazyny-gazu/[dostęp 28.09.2015 r.].

[3] http://www.gaz-system.pl/o-firmie/informacje-podstawowe/ [dostęp 28.09.2015 r.].

[4] http://www.gaz-system.pl/terminal-lng/ [dostęp 28.09.2015 r.].

[5] Najwyższa Izba Kontroli: Prawidłowość nadzoru nad bezpieczeństwem eksploatowanych gazociągów oraz prowadzenia nowych inwestycji przez spółkę Gaz -System S.A. KG P 4114-001-00/2014, Nr ewid. 4/2015/I/14/003/KGP. 
[6] Pietrucha-Urbanik K., Tchórzewska-Cieślak B.: Research methodology of water network failure in terms of reneval. Metodologia badania awaryjności sieci wodociągowej w aspekcie jej odnowy. Journal of KONBiN 1(33)2015, s. 233-242. DOI 10.1515/jok-2015-031.

[7] Rak J.: Metoda planowania remontów sieci wodociągowej na przykładzie miasta Krosna, Czasopismo Inżynierii Lądowej, Środowiska i Architektury, JCEEA, t. XXXI, z. 61 (1/14), 2014, s. 225-232. DOI:10.7862/rb.2014.15.

[8] Rozporządzenie Ministra Gospodarki z dnia 26 kwietnia 2013 r. w sprawie warunków technicznych, jakim powinny odpowiadać sieci gazowe i ich usytuowanie, Dz.U. 2013, nr 0, poz. 640.

[9] Studziński A., Pietrucha-Urbanik K., Mędrala A.: Analiza strat wody oraz awaryjności w wybranych systemach zaopatrzenia w wodę, Czasopismo Inżynierii Lądowej, Środowiska i Architektury, JCEEA, t. XXXI, z. 61 (4/14), 2014, s. 193-201. DOI:10.7862/rb.2014.144.

[10] Tchórzewska-Cieślak, B., Pietrucha-Urbanik, K.: Poziomy nienaruszalności bezpieczeństwa w systemach zbiorowego zaopatrzenia w wodę. Instal 12, 2014, s. 109112.

[11] Tchórzewska-Cieślak B., Pietrucha-Urbanik K., Bajer J.: Crisis situation management issues in urban areas water supply, Journal of Polish Safety and Reliability Association, Summer Safety and Reliability Seminars, vol. 6, no 2, 2015, pp. 135146.

[12] Urbanik M., Tchórzewska-Cieślak B.: Ecological aspects of the natural gas use, Czasopismo Inżynierii Lądowej, Środowiska i Architektury, JCEEA, t. XXXII, z. 62 (1/15), 2015, s. 409-418.

[13] Urbanik M., Tchórzewska-Cieślak B.: Podstawy analizy niezawodności funkcjonowania instalacji wykorzystujących gaz ziemny, Czasopismo Inżynierii Lądowej, Środowiska i Architektury, JCEEA, t. XXXII, z. 62 (1/15), 2015, s. 419431. DOI: $10.7862 / \mathrm{rb} .2015 .30$. DOI: $10.7862 / \mathrm{rb} .2015 .29$.

[14] Zintegrowany raport roczny 2013: Gaz-System.

\section{ANALYSIS OF PIPELINE GAS INFRASTRUCTURE AND EMERGENCY EVENTS IN GAS SUPPLY SUBSYSTEM IN POLAND}

\section{S u m m a r y}

The increasing demand for energy also causes increasing emissions of pollutants into the atmosphere. Therefore, one should look for such sources of energy that will cause less pollution. Such energy source is natural gas, which during combustion produces less harmful substances in comparison to oil or coal. For this reason this fuel is finding increasing use in industry, automotive industry or in private households. Due to the increasing use it appears advisable to reduce the risk of pipeline failure, because any failure interferes with the supply of the fuel, and it also can interfere with customers. The failure of the pipeline is likely to have serious consequences in the form of material damage or killed people. An example is the failure in Janow Przygodzki, as mentioned in the article.

The paper presents an analysis of the gas infrastructure state, which occurred in Poland. The study highlights the factors which causes emergency events and its analysis. The causes of failure 
events in the natural gas distribution subsystem are for example: poor technical condition of pipelines and errors associated with the operator management.

Keywords: emergency events, the gas supply subsystem, failure cause, the state of gas infrastructure

Przestano do redakcji: 13.10.2015 $r$.

Przyjęto do druku: $30.10 .2015 \mathrm{r}$.

DOI: $10.7862 / \mathrm{rb} .2015 .131$ 